\title{
Observations on the translation process of trichostrongylid nematodes
}

\author{
J. Pacenovsky ${ }^{1}$, A. Kloosterman ${ }^{1}$ and H. W. Antonisse ${ }^{2}$ \\ 1 Department of Animal Husbandry, Agricultural University, Wageningen, \\ the Netherlands \\ 2 Faculty of Veterinary Medicine, State University, Utrecht, the Netherlands
}

Received: 22 March 1971

\begin{abstract}
Summary
An experiment was carried out in which faeces with a ccrtain, constant concentration of eggs of Cooperia spp. and Ostertagia spp. were deposited as artificial pats on grassland every two weeks through the grazing season.

Weekly larval counts on grass in the immediate surroundings of the faecal pats during the grazing season indicated that the larval concentrations are positively related to soil temperature and rainfall, and negatively to air temperature and radiation. The typical seasonal course of pasture infections was seen if the results of the various series were summed. On the average it lasted 9-10 weeks before maximum numbers of larvae were observed. Faeces deposited in autumn were the main source of overwintered infection.
\end{abstract}

\section{Introduction}

The translation-process defined by Rose (1963) as the process whereby trichostrongylid eggs in faeces become infective larvae on herbage, available for the host, is extremely important for the understanding of the epidemiology of trichostrongylosis. Many studies on this problem, including laboratory experiments and investigations of outdoor grassplots as well as grazing experiments, have been conducted. In most of these studies the minimum time for development and migration and the maximum time of survival have been emphasized. The time at which maximum numbers of larvae are found on the herbage has received less attention. This variate is difficult to estimate, for the amount of larvae is the result of a continuous process of new development and migration on one hand and dying of larvae on the other.

Both processes are influenced by climatic factors. It is known that temperatures of at least $10^{\circ} \mathrm{C}$ are necessary for satisfactory development of eggs to infective larvae, bu: tomperatures above $25^{\circ} \mathrm{C}$ have an adverse effect on survival of larvae (Ciordia and Bizzcll, 1963; Rose, 1963, 1966). Rainfall may, in hot and dry climates, be important for development, but it is also a requirement for the migration of larvae out of the faeces (Rose, 1963).

Michel (1969) showed in grazing experiments during several years, a remarkably

* Present address: Helminthological Institute, Dukelskych hrdinov 11, Kosice, Czechoslovakia. 
constant seasonal pattern of herbage infestation and he considered the mid-summer increase of larval concentrations to be the main cause of clinical parasitic gastro-enteritis. Eggs deposited early and late in the grazing season were relatively unsuccesful in development or, at least did not contribute as much to disease production.

It is known that the majority of larvae, although some of them may migrate laterally for appreciable distances, remain in the immediate surroundings of the faecal pat (Durie, 1961; Rose, 1963, 1966).

A study on larval numbers in the herbage around artificial faecal pats is reported below. This experiment was an attempt to find out how the time of exposure and climatic factors influence the translation process, and how these factors give rise to a seasonal pattern of herbage infestation.

\section{Materials and methods}

Starting on 16 May 1969, a series of 5 artificial faecal pats was placed on grass plots every two weeks (see Fig. 1). The plots were on grassland that had carried no stock for at least 10 years. The distance between pats was $2 \mathrm{~m}$. The pats were about $5 \mathrm{~cm}$ high, had a diameter of $20 \mathrm{~cm}$, were of normal consistency, weighed $500 \mathrm{~g}$, and contained an approximately constant number of eggs. The faeces were taken from calves that had been artificially infected with a mixture of Cooperia spp. $(90 \%)$ and Ostertagia spp. $(10 \%)$. They were mixed with a certain amount of faeces from older cattle with zero egg counts, in order to obtain an egg concentration of 500 e.p.g. The e.p.g.-values were determined by a $\mathrm{ZnSO}_{4}$ floatation technique, described by Kloosterman (1971), which had a recovery rate of $55 \%$.

The facces were deposited in series of 5 pats, to avoid as much as possible differences between series with respect to botanical composition of the grass. Prior to depositing the faeces, each plot was mown with a lawn-mower, so that each series started at a comparable stage of grass growth.

From each series samples were taken in duplo from 8.30 to 11.30 a.m., every week. A sample was collected by plucking, between thumb and forefinger, all the herbage within 10 quadrats of $25 \mathrm{~cm}^{2}$ ( 2 quadrats near each of the 5 faecal pats). The centres of these quadrats were chosen with the aid of a random number table out of 160 possible positions, characterized by 16 directions and by 10 distances from the edge of the faecal pat. This procedure was considered necessary, as systematic sampling might interfere with microclimatic conditions and migratory activities of the larvae. The fresh herbage samples were weighed and processed further according to the method described by Kloosterman (1971).

The intention was originally to confine the above mentioned observations to the grazing season which, in the Netherlands, lasts from early May until the end of October, but also during the following winter season some occasional samplings have been carried out.

Meteorological data were provided by the Department of Meteorology of the Agricultural University, Wageningen. The site of climatic observations was $840 \mathrm{~m}$ from the field where the trial was carried out, and on the same type of clay soil.

\section{Results}

Fig. 1 presents the results of larval counts expressed as larvae per kg herbage. It clearly indicates that the efficiency of translation differed between series. The early Series 


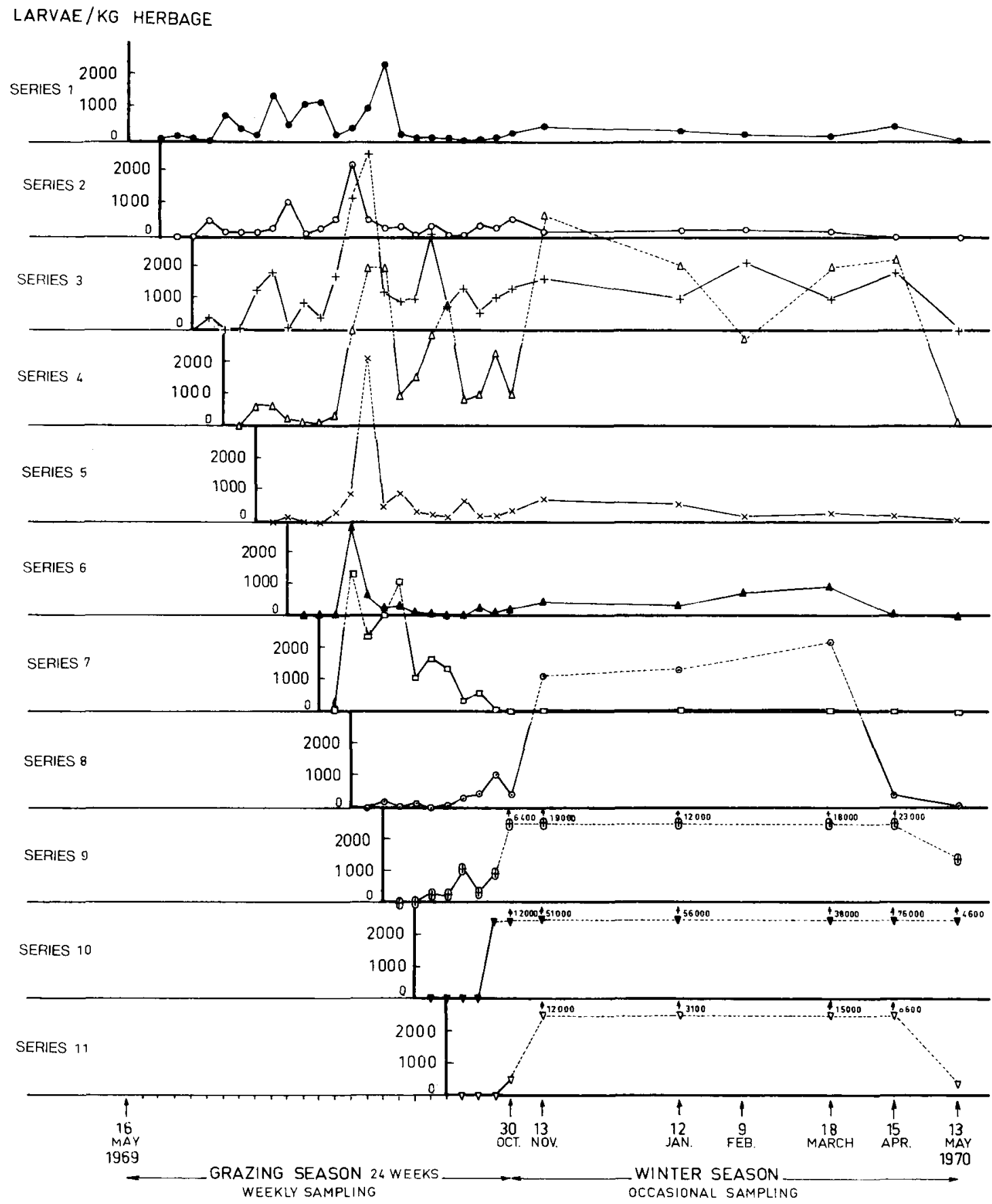

Fig. 1. The experimental lay-out and results of untransformed larval counts. 
1 and 2 seem to have been less succesful than Series 3 and 4 . Also the difference between Series 7 and 8 is remarkable, particularly because only two weeks elapsed between them. Such differences should be attributed to climatic conditions. In addition it is clear that Series $8,9,10$ and 11 were not successful at the start but showed extremely high numbers of larvae during the winter season, when compared to earlier series. From Fig. 1 also an impression of the distribution of larval counts may be obtained; clearly a transformation of counts is necessary before proceeding with the statistical treatment of the results. Such examinations, carried out below for the influence of distance, of climatic factors and of exposure time, refer only to the samples taken weekly during the grazing season.

\section{Influence of distance from faecal pat}

For each sample the sum of distances of grass-pinches was known. The variation between duplicate samples taken from each series under the same weather-conditions revealed a significant negative correlation $(r=-0.25, \mathrm{P}<0.01)$ between number of larvae and distance.

\section{Influence of climatic factors}

Let $\mathrm{t}$ be the time (weeks) elapsed after depositing the faeces, than all observations can be classificd according to $t$. The number of observations within such ' $t$ '-classes varies from 11 to 1 (see Fig. 1). Let $y=\ln 100(n+1) / g$ be the larval concentration. Here, $g$ is the weight (grammes) of the two duplicate herbage samples and $n$ is the sum of the 4 counts performed in these samples. The factor 100 was chosen because this was near to the mean of the sample weights; $n+1$ was used in order to include zero counts in the statistical examination.

The factors considered were: $X_{L}$ (distance), $X_{T s}$ (soil temperature), $X_{T a}$ (air temperature), $X_{R}$ (rainfall), $X_{D}$ (dew-point) and $X_{R a d}$ (radiation).

Some further precision of these factors is necessary:

$\mathrm{X}_{\mathrm{L}}$ is the sum of the distances of 20 grass-pinches that constitute the two herbage samples, in units of $3 \mathrm{~cm}$. Its mean value over all observations during the grazing season was $\mathrm{X}_{\mathrm{L}}=111.2$, which means that on the average a pinch of grass is taken $111.2 \times 3 / 20 \mathrm{~cm}=16.7 \mathrm{~cm}$ from the edge of the faecal pat;

$\mathrm{X}_{\mathrm{Ts}}$ is the soil temperature $\left({ }^{\circ} \mathrm{C}\right)$ averaged over 7 days prior to the observation, measured daily, 8.40 a.m., $10 \mathrm{~cm}$ below ground level. Mean over experimental period (MayOct.): $15.6^{\circ} \mathrm{C}$;

$\mathrm{X}_{\mathrm{Ta}}$ is the air temperature $\left({ }^{\circ} \mathrm{C}\right.$ ), daily maximum temperature measured $10 \mathrm{~cm}$ above ground level, averaged over 7 days preceding the observation. Mean over experimental period (May-Oct.): $22.7^{\circ} \mathrm{C}$;

$X_{R}$ is the rainfall $(\mathrm{mm})$ summed over the 7 preceding days. Mean: $11.03 \mathrm{~mm}$ over the entire experimental period (May-Oct.);

$\mathrm{X}_{\mathrm{D}}$ is the dew-point $\left({ }^{\circ} \mathrm{C}\right)$ averaged over 7 days prior to observation. Mean over experimental period (May-Oct.): $11.7^{\circ} \mathrm{C}$;

$\mathrm{X}_{\mathrm{Rad}}$ is the radiation $\left(\mathrm{cal} / \mathrm{cm}^{2}\right)$ averaged over the 7 preceding days. The mean over the entire period (May-Oct.) was: 295.0.

Within each of the ' $t$ ' classes intercorrelations between $y$ and the mentioned factors were calculated. For the various classes no appreciable differences were observed between the correlation-matrices. Therefore, after pooling the $\mathrm{X}$ observations and replacing the y values by the deviations $A(\mathrm{y})$ from their subsequent $(\mathrm{t})$ class means, the 
Table 1. The correlations between $\Delta(\mathrm{y})$ and distance and various climatic conditions.

\begin{tabular}{lllllll}
\hline & $\mathrm{X}_{\mathrm{L}}$ & $\mathrm{X}_{\mathrm{Ts}}$ & $\mathrm{X}_{\mathrm{Ta}}$ & $\mathrm{X}_{\mathrm{R}}$ & $\mathrm{X}_{\mathrm{D}}$ & $\mathrm{X}_{\mathrm{Rad}}$ \\
$\mathrm{X}_{\mathrm{Ts}}$ & -0.109 & & & & & \\
$\mathrm{X}_{\mathrm{Ta}}$ & -0.096 & +0.844 & & & & \\
$\mathrm{X}_{\mathrm{R}}$ & -0.027 & +0.287 & -0.126 & & & \\
$\mathrm{X}_{\mathrm{D}}$ & -0.022 & +0.599 & +0.615 & -0.007 & & \\
$\mathrm{X}_{\mathrm{Rad}}$ & -0.094 & +0.753 & +0.726 & +0.085 & +0.234 & \\
$\Delta \mathrm{y}$ & -0.267 & +0.095 & -0.118 & +0.294 & +0.071 & -0.059 \\
\hline
\end{tabular}

correlation matrix was recalculated (see Table 1). Only the variables $X_{L}$ and $X_{R}$ gave significant correlations with $\Delta(\mathrm{y})(\mathrm{P}<0.01)$.

Calculation of a linear multiple regression equation for $\Delta(\mathrm{y})$ on all the variables revealed that they all except $\mathrm{X}_{\mathrm{D}}$ reduced the residual variance of $\Delta(\mathrm{y})$ significantly. This equation took the form

$$
\begin{aligned}
\Delta^{*}(\mathrm{y})= & 2.323-0.02646 \mathrm{X}_{\mathrm{L}}-0.1913 \mathrm{X}_{\mathrm{Ta}}+0.3578 \mathrm{X}_{\mathrm{Ts}} \\
& +0.001719 \mathrm{X}_{\mathrm{R}}-0.001896 \mathrm{X}_{\mathrm{Rad}}
\end{aligned}
$$

in the above-mentioned units.

If for all variables the means over the entire experimental period are substituted $\Delta(\mathrm{y})$ becomes zero, apart from rounding errors.

The relative importance of the different factors in this relation can be judged by the product of the coefficients with the standard deviation of the subsequent variable. These values are: $\mathrm{X}_{\mathrm{L}}(-0.337), \mathrm{X}_{\mathrm{Ta}}(-0.783), \mathrm{X}_{\mathrm{Ts}}(+0.906), \mathrm{X}_{\mathrm{R}}(+0.0257)$ and $\mathrm{X}_{\mathrm{Rad}}(-0.221)$.

As far as a linear model is appropriate it seems that within the range of the climatic conditions in our experiment soil and air temperature are most important for the translation process and influence it in opposite directions.

Only $23 \%$ of the variance of $A(y)$ is accounted for by the equation $(\mathrm{R}=0.48$, $\mathrm{F}(6 ; 121)=6.03, \mathrm{P}<0.001)$. This leaves a standard deviation of about $1.2 \mathrm{n}$ if the expected number of larvae equals $n$.

Fig. 2 presents the course of transformed larval counts in relation to the prevailing weather conditions.

The influence of time interval for which faeces have been exposed

The function

$\mathrm{f}(\mathrm{t})=\ln \left[1+\mathrm{A}\left(\mathrm{t}-\mathrm{t}_{\mathrm{o}}\right)^{\alpha} \times \mathrm{e}^{-\beta\left(\mathrm{t}-\mathrm{t}_{\mathrm{o}}\right)}\right]$

gives an empirical approach of the number of larvae that can be found on the herbage around faecal pats $t$ weeks after the faeces are deposited; $t_{0}$ denotes the number of weeks that elapse before the first larvae appear, $\mathbf{A}$ is a constant, $\alpha$ and $\beta$ provide a measure for the supply and flow-off of larvae, respectively. The derivative of the function $f(t)$ takes the value 0 on three occasions, namely when $t_{0}=t_{0}$, when $t=$ $\alpha / \beta+\mathrm{t}_{\mathrm{o}}$ and when $\mathrm{t}=\infty$.

After the observed larval concentrations had been corrected for distance and climatic factors according to Eq. 1, the function $f(t)$ could be estimated by minimalization of $\Sigma \mathrm{d}^{2}$, the sum of squares of deviations from $\mathrm{f}(\mathrm{t})$ of cach of the corrected values. This 


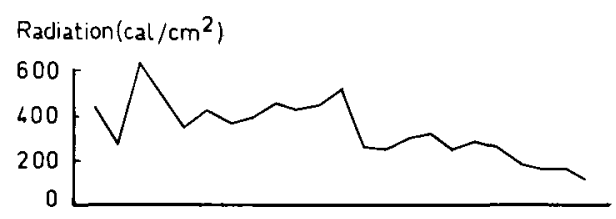

Fig. 2. The seasonal course of the larval concen. tration, in relation to climatic conditions.
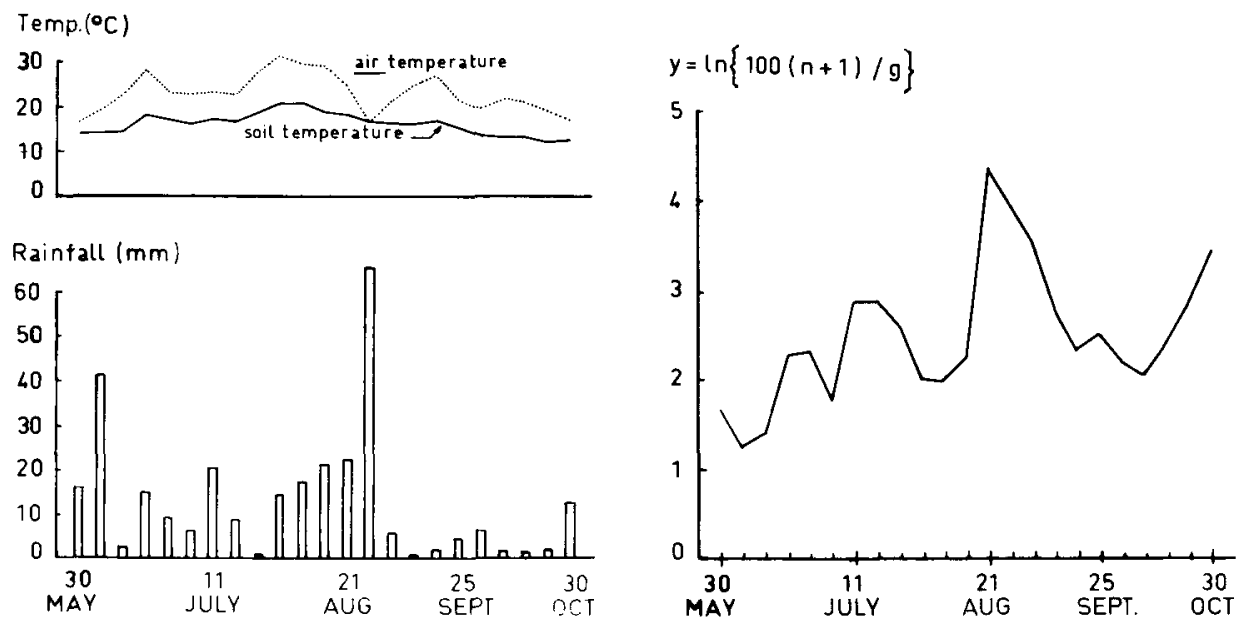

estimation resulted in $\mathrm{A}=2.998, \mathrm{t}_{\circ}=0.7124, \alpha=1.717$ and $\beta=0.1914 ; \alpha$ and $\beta$ proved to decrease the residual variance significantly, the other factors did not.

On basis of this experiment, the first larvae can be expected after $t_{0}=0.71$ weeks

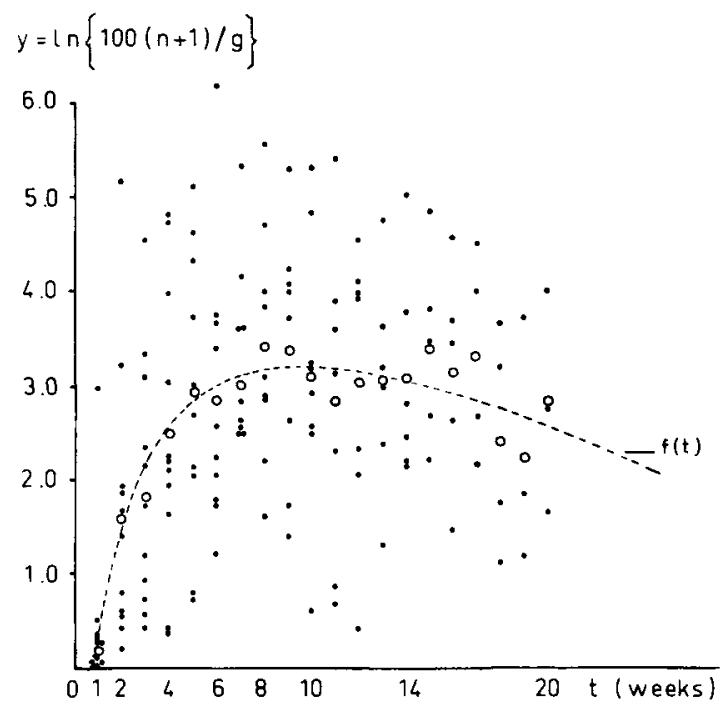

Fig. 3. The course of larval concentration in relation to the time-interval of exposure (.$=$ uncorrected transformed values, $0=$ means $)$. 
$\approx 5$ days, and after $\mathrm{t}=\alpha / \beta+\mathrm{t}_{\mathrm{o}}=9.68$ weeks maximum numbers of larvae can be found. This is illustrated by Fig. 3, where $f(t)$ is drawn, with the results of the noncorrected observations and their means. It is clear that considerable deviations from the ideal curve exist, and although much of this variation can be ascribed to distance and climatic factors, there is also considerable variation due to sampling and technical error.

The contribution of each series to herbage infestation

Table 2 gives for each series the relative contribution to herbage infestation (expressed as transformed counts) observed during the grazing season. This contribution is of course highly depending on the time of exposure and therefore the contribution which might be expected on the basis of the number of observations is also included in the table. It is clear that the early series are in particular responsible for the infestation and therefore for the hazards of auto-infection by calves during their first grazing season. Table 2 presents also the relative contribution of the various series to overwintered infection, measured in March, April and May of the following year. Clearly, the late series, deposited after August can be considered as the main source of overwintered infection.

Table 2. Contribution of each series to the observed infestation (\%).

\begin{tabular}{|c|c|c|c|c|c|}
\hline \multirow[t]{2}{*}{ Series } & \multirow[t]{2}{*}{$\begin{array}{l}\text { Date of } \\
\text { exposure }\end{array}$} & \multirow{2}{*}{$\begin{array}{l}\text { Number of } \\
\text { observations } \\
\text { during grazing } \\
\text { season }\end{array}$} & \multicolumn{2}{|c|}{$\begin{array}{l}\text { Relative contribution } \\
\text { to infestation during } \\
\text { the grazing season }\end{array}$} & \multirow{2}{*}{$\begin{array}{l}\text { Relative } \\
\text { contribution } \\
\text { to over- } \\
\text { wintered } \\
\text { infestation }\end{array}$} \\
\hline & & & $\begin{array}{l}\text { expected on } \\
\text { basis of } \\
\text { number of } \\
\text { observations }\end{array}$ & observed & \\
\hline 1 & 16 May & 23 & 15.0 & 15.3 & 5.2 \\
\hline 2 & 30 May & 22 & 14.4 & 12.5 & 2.9 \\
\hline 3 & 13 June & 20 & 13.1 & 17.2 & 9.9 \\
\hline 4 & 27 June & 18 & 11.8 & 14.9 & 14.0 \\
\hline 5 & $11 \mathrm{July}$ & 16 & 10.5 & 9.4 & 5.8 \\
\hline 6 & $25 \mathrm{July}$ & 14 & 9.2 & 6.8 & 4.1 \\
\hline 7 & 7 Aug. & 12 & 7.8 & 10.3 & 1.6 \\
\hline 8 & 21 Aug. & - 10 & 6.5 & 5.3 & 8.8 \\
\hline 9 & 4 Sept. & 8 & 5.2 & 5.2 & 15.9 \\
\hline 10 & 18 Sept. & 6 & 3.9 & 2.4 & 18.6 \\
\hline \multirow[t]{2}{*}{11} & 2 Oct. & 4 & 2.6 & 0.6 & 13.2 \\
\hline & & & 100.0 & 99.9 & 100.0 \\
\hline
\end{tabular}

\section{Discussion}

The influence of distance from faeces and climatic factors on larval infestation is in good agreement with the literature. It may be assumed that soil temperature is the 
factor of special importance for development of eggs to infective larvae (Kutzer, 1967; Rose, 1961, 1963). Rainfall likely plays an important role in the migration of larvae from the faeces to the herbage (Rose, 1963). From the regression equation 1 and the mean and variation of these two factors, it might be suggested that soil temperature exerts more influence on larval numbers than rainfall does. This would support the fact that the seasonal pattern is so remarkably constant from year to year. On the other hand the season of 1969 was rather dry, particularly during September and October, and this prevented the migration of larvae in the series deposited after August (Fig. 1); and after 30 October a dramatic rise was observed on these series. All this means that the results may not be generalized.

Air temperature near ground level and radiation, which are interrelated positively, are both negatively related to larval infestation. This is in good agreement with the results reported in literature, and the negative relationship is generally ascribed to increased activity of larvae and to desiccation or alternate wetting and desiccation of larvae. The very high numbers found during the colder months (Fig. 1) suggest that low temperatures are in favour of survival. The rapid decrease from April to May 1970 is also mainly due to rising temperatures, although dilution by grass growth has also played a small role.

The whole experiment may, to a certain degree be considered as a model of a pasture grazed continuously by calves which have a constant egg excretion during the entire season. The course of larval infestation (Fig. 2) is in good agreement with the seasonal curves found on calf pastures (Michel, 1969; Kloosterman, 1971).

It is impossible to indicate what level of infestation will be dangerous for grazing calves. Not only because in this experiment samples were taken from grass that is usually avoided by grazing animals, but also in case of random sampling of natural pastures, the reaction of calves on a certain larval concentration cannot be predicted. It depends on the resistance of the animals and on the degree to which they are forced to eat heavily contaminated herbage. This, in return is governed by grazing intensity (number of calf-days per ha) and grass-growth.

Given the large variation around the $\mathrm{f}(\mathrm{t})$ curve drawn in Fig. 3, it can also not be predicted when and how long a pasture will be dangerous. The fact that maximum numbers of larvae occurred after 9-10 weeks suggests strongly however, that it can be extremely dangerous to return to a pasture when the grass has regrown after a previous grazing. This is in good agreement with the results of Donald (1967) and other workers on the subject of rotational grazing.

Finally the experimental results suggest that overwintered infection, which is probably of epidemiological significance in the Netherlands (Kloosterman, 1971), results mainly from faeces deposited during the autumn months. This is not in agreement with the results of Michel (1969) and Michel et al. (1970), which can probably be ascribed to the species. These authors worked with infections where Ostertagia ostertagi predominated or showed a fifty-fifty ratio with Cooperia oncophora in the faeces. The last mentioned species was, however, predominant in the faeces laid out in this experiment $(85-95 \%)$. It is known that this species is more successful in overwintering than O. ostertagi (Rose, 1961, 1963; Kutzer, 1967; Kloosterman, 1971).

\section{Acknowledgment}

The technical assistance of Mr R. van den Brink is gratefully acknowledged. 


\section{References}

Ciordia, H. \& W. E. Bizzell, 1963. The effect of various constant temperatures on the development of the free living stages of some nematode parasites of cattle. J. Parasit. 49: 60-63.

Donald, A. D., 1967. Populations of strongyloid infective larvae in pastures after sheep are removed from grazing. Aust. vet. J. 43 : 122-128.

Durie, P. H., 1961. Parasitic gastro-enteritis of cattle: The distribution and survival of infective strongyle larvae on pasture. Aust. J. agric. Res. 12: 1200-1211.

Kloosterman, A., 1971. Observations on the epidemiology of trichostrongylosis of calves. Thesis, Wageningen. Meded. LandbHogesch. Wageningen 71-10.

Kutzer, E., 1967. Biologie und Oekologie der präparasitären Entwicklungsstadien von Ostertagia ostertagi und Cooperia oncophora (Nematoda, Trichostrongylidae) im Hinblick auf die Epidemiologie der Trichostrongylidose der Rinder. Wiener Tierärztl. Mschr. 54: 164-181; 315-332.

Michel, J. F., 1969. Observations on the epidemiology of parasitic gastro-enteritis in calves. J. Helminth. 43: 111-133.

Michel, J. F., M. B. Lancaster \& C. Hong, 1970. Field observations on the epidemiology of parasitic gastro-enteritis in calves. Res. vet. Sci. 11: 255-259.

Rose, J. H., 1961. Some observations on the free living stages of Ostertagia ostertagi a stomach worm of cattle. Parasitology 51: 295-307.

Rose, J. H., 1963. Ecological observations and laboratory experiments on the free living stages of Cooperia oncophora. J. Comp. Path. 73: 285-296.

Rose, J. H., 1966. Investigations into the free living phase of the life cycle of Nematodirus helvetianus. Parasitology 56: 679-691. 